\title{
Cultural Diversity., Public Space, Aesthetics and Power
}

\section{Emine Onaran Incirlioglu \& Zerrin G. Tandogan}

To cite this article: Emine Onaran Incirlioglu \& Zerrin G. Tandogan (1999) Cultural Diversity., Public Space, Aesthetics and Power, European Journal of Intercultural Studies, 10:1, 51-61, DOI: 10.1080/0952391990100105

To link to this article: https://doi.org/10.1080/0952391990100105

曲 Published online: 23 May 2006.

Submit your article to this journal $\pi$

Џll Article views: 217

Citing articles: 2 View citing articles $\widetilde{ }$ 


\title{
Cultural Diversity, Public Space, Aesthetics and Power
}

\author{
EMINE ONARAN INCIRLIOGLU \& ZERRIN G. TANDOGAN
}

ABSTRACT In this paper we argue that issues of inclusion and exclusion to public space can be examined by invoking the principle of "aesthetics". Those that are aesthetically pleasing, tasteful, or desirable are allowed in public spaces, yet these characteristics are defined through social and cultural mechanisms. Differences between cultural groups in terms of body movement, proximity relationships, definition of personal space, clothing, and other visible features, are evaluated and judged through the filter of power relations. Numerous non-European migrants who reside in the North experience discrimination as a result of being "visible foreigners". They are not welcome in public areas and they do not meet the prevalent aesthetic standards, defined by the dominant discourse around aesthetics. This trend obstructs the development of multicultural coexistence and the possibility of transnationalism. In order to realise cultural expression for all, we extend an invitation to scrutinise power inequalities by means of multicultural educational programs.

"It is impossible to begin to learn that which one thinks one already knows."

Epictetus

Current discussions regarding the issue of cultural diversity have served to expose a set of questions concerning the imposition of aesthetic values in public spaces, The existing power structure determines how this diversity is experienced in public spaces, and what the implications of these experiences are for public policy-makers. Our intention in this paper is to focus on the negatives of multiculturalism and to call the reader's attention to the experiences of the "Other" in the public spaces of culturally diverse cities of the world at the end of the twentieth century.

\section{Cultural Diversity: Cosmopolitanism or Multiculturalism?}

We can list a number of scenarios that delineate the concept of "cultural diversity." One of these scenarios is best defined by the concept of cosmopolitanism, as described by Ulf Hannerz: "... cosmopolitanism is first of all an orientation, a willingness to engage with the Other. It is an intellectual and aesthetic stance of openness toward divergent cultural experiences, a search for contrasts rather than uniformity" (Hannerz, 1990). This depiction refers to an attitude which enables a harmonious coexistence of diverse cultures in the world. Individuals can develop an 
understanding of other cultures, which are no longer seen as "Other" since they have become an integral part of a cosmopolitan identity.

Another contemporary approach to cultural diversity, as it can be understood by using the concept multiculturalism, focuses on the existence of various ethnic communities within a given territory whose cultural claims are recognised and respected by the host state. Nowadays, multiculturalism is "in", that is to say, much more popular than cosmopolitanism among both multiculturalist policy-makers and academicians in discussions relating to cultural diversity.

In this paper, we discuss multiculturalism within the context of non-European immigrants in countries where multiculturalism is declared to be a state policy, a worldview, or a longing for an improvement of human relations in the future. For example, a common tendency among Europeans is the association of non-European immigrants with the term "multiculturalism". As Vertovec has stated, "since the 1970s multiculturalism has emerged as a term increasingly called upon in parliamentary debates and political party manifestos, the rhetoric of ethnic group leaders, the logic of local government structuring and budgeting, social scientific analysis, popular media, and commercial marketing" (Vertovec, 1996, p. 50). It is not a coincidence that the discourse around multiculturalism and the growth of the number of non-European immigrants are taking place at about the same time, as if they are the only ones who create heterogeneity in these nation-states. Viewed in this manner, cultural diversity, interchangeably used with multiculturalism in this paper, somehow gains a negative connotation. These immigrants are treated by society as scapegoats and their presence is questioned whenever an immigrant happens to be involved in an act that is considered to be illegal, indecent, improper, or immoral. Media involvement only helps to reinforce the existing images of these people and creates a self-fulfilling prophecy.

\section{The European Context}

While Europe is taking on the challenge of coming to terms with its own cultural diversity during the present process of unification, the "problem" of non-European residents continues to bother the creators of this new European edifice. As a matter of fact, one of the measures taken against immigration is to tighten the borders and to build a so-called "Fortress Europe". The immigrants already residing in Europe with the status of either denizen or guest worker have not been integrated, at least not willingly, into this new notion of a unified Europe. Although Europe has had a long-standing history of contact with other cultures, there still exists a fear of foreigners, which is exemplified by the treatment of immigrants. This historical experience does not seem to be a sufficient remedy to overcome the dilemma between xenophobia and multiculturalism. On the contrary, the present occurrence of xenophobia may be precisely the result and continuation of past contacts. Our intention here is not to discuss the long-lasting consequences of colonialism for the coloniser. In any case, as it is indicated in a textbook used by The Open University, "cultural autonomy" is held in high regard by Europeans:

On the one hand contacts between cultures have become closer, they seem to have come to resemble each other. Because of the effects of modern 
technology and modern media, through travel and everyday intercultural contacts, through the experience of different patterns of everyday behaviour and standards, many differences seem to have become relative and reduced to common factors. On the other hand, this "natural" convergence and mixing of cultures also generates defensive attitudes. Some of these come about because of the infiltration of foreign elements into our everyday environment, but some are also the result of the planned coalescence of Europe ... We are still very much dependent on the idea of cultural autonomy, which now seems to be threatened both by too much variety and too much uniformity (Shelley $\&$ Winck, 1993).

In our view, the lack of cosmopolitanism and the limited understanding of multiculturalism are obstacles to the improvement of multicultural human contacts. The isolation, discrimination and the marginalisation of foreign elements from European culture results in the separation and ghettoisation of these immigrant communities from the majority, from societal public spaces and from sharing a common meaning for all. The notion of multiculturalism which seems to be politically correct, at least for liberals and democrats, has not yet become an integral part of everyday practices. In fact, there is more evidence indicating that disintegration rather than integration is taken place. We have an urge to point this out because we are afraid that cultural diversity and cultural disintegration will be inevitably linked.

At this point, we shall address the unfair treatment of non-European immigrants in a so-called multicultural society on the basis of cultural difference. Vivid descriptions of these immigrants' personal experiences may help us see how power relations are articulated on the basis of such differences.

\section{Diverse Experiences}

Many "real life" stories demonstrate that different people have different experiences in the very same public spaces. This diversity in experiences may be explained by a host of factors such as personal idiosyncrasies, cultural diversity, social status and economic class. Underlying this seemingly innocent "diversity" of experiences, however, we can find inequalities in the domains of participation and power.

Let us take a magnificent new shopping centre as an example. It provides diverse experiences for many customers, who eat in the restaurants and cafes of their choice, shop in the numerous stores for a variety of consumer goods, or just window-shop to pass the time. If, however, the security guard at the entrance deems you inappropriate for this environment, you would face a different set of experiences: rejection, deprivation and humiliation. It is likely that class differences underlie this diversity in experience.

In other instances, clear-cut class-related explanations are more difficult. For example, when Turkish workers in Germany are, either implicitly or explicitly, excluded from such public places, sometimes even from certain parks and streets, are they discriminated against on the basis of class, or on the basis of "culture" and "race"? 
There are a number of foreign intellectuals, students, artists and professionals in Europe, who also report experiences of similar degradation. Class cannot explain their discrimination. We have encountered countless examples from first-hand experience and from our conversations with others in Turkey. Here are a few examples:

"I had a friend who came from an aristocratic family and was a graduate of the German High School in Istanbul. His father was a Turk and his mother was Italian. His wife was also from Italy and they lived in Germany. Although he was a successful musician at the Freiburg Conservatory, he felt uncomfortable living in Germany. The kind of discomfort was somewhat subtle, yet once he said to me, "do you think it is possible to live with these people and not feel uncomfortable?"

Recently there was an interview in the Turkish daily Hürriyet with Fazil Say, a successful, young Turkish pianist who went to Germany at age 17 with a distinguished music scholarship, graduated at age 21 as the first in his class, started teaching at the Berlin Music Academy at age 22, and has won numerous international awards. Fazil Say, who lived in Germany for 7.5 years before settling in New York, explicitly states in this interview that he suffered much hardship, and observed more xenophobia and antagonism towards foreigners in Germany than he had observed anywhere else (Hürriyet, Sunday Supplement, 15 March 1998).

Some immigrants, perhaps eventually all who have settled in Germany, have learned to accept such second-class treatment. For example, a university-educated Turkish woman who lived in Freiburg for 3 years in the mid 1980s, as a young woman with her husband and infant daughter, was not particularly distressed about her experiences. "Nothing really terrible has happened to me", she said. "They would not sit next to me on the bus, that's all." She was not complaining about this rejection or lack of attention, because she was comparing her experiences with other cases of a different magnitude. "But there were those who really suffered", she continued, "I had an Iranian friend; they put out a cigarette on her son's arm. But then they were some of those really racist Germans, who travel from one city to the next to make trouble and cause turmoil."

"German racism" is a common phrase we hear in Turkey. Yet more subtle forms of racism have also been observed in various other settings. The following is what a Turkish engineer reported to us after one of his business trips to the South of Norway, famous for its religious conservatism: "Sunday was my day off and while going around the city I saw an Evangelist church. The entrance was crowded with people who were properly dressed", he said and continued, "I noticed a poster about a concert of Bach cantatas which would be performed in that church. I entered the church without hesitation." Immediately after he seated himself, the lady next to him started looking at him with an obvious curiosity, and during the intermission she asked him in a sympathetic manner, in English, if he was of the Evangelical persuasion, too. "I said, 'no I am not.' Then she asked if I was a Catholic. When I said I was not, she stopped smiling and rhetorically asked, 'but you are Christian aren't you?' 'No, in fact I am Muslim', I said and added that I was there just to listen 
to the cantatas. She said 'oh yeah!' and that was the end of the conversation. She never looked to my side again and never talked to me."

Using methods ranging from explicitly racist and violent force, to subtly exclusive behaviour, the participation of certain unwanted groups in public spaces has been widely restricted. Moreover, in addition to visual discrimination, there are also restrictions which are olfactory and auditory. If, for example, ezan, the Muslim call for prayer, is considered to be a disturbing noise and not allowed in certain North American or European cities where church bells are welcome, this is nothing but auditory discrimination (see also Metcalf, 1996). If, for example, the smell of onion or garlic is considered to be repulsive, those people whose cuisine includes garlic and onion as major ingredients will be discriminated against. One of our informants reported that, in the 1960 s, Italians and presently Turks in Germany were called "Knoblauch fresser" ('garlic eater'). "So the Germans do not eat garlic?" we rhetorically asked. "No they do not. They swallow garlic pills", she answered. In fact, the advertisement text for the garlic pills said "garlic smells but the garlic pills do not". The contract for a condominium housing complex in South Central Florida included an item that disallowed residents to cook "smelly food" on the grounds that "the odour" would disturb the condominium residents. Most residents considered this quite "normal," without questioning who would define "smelly food"? Probably they agreed that curry, garlic and deep-fried pork would "smell," but apple pie would not.

Discrimination based on taste, smell and food is not restricted to Europe and North America. Food has always been used to draw, maintain, or erase boundaries between groups of all sorts. It is also used by individuals. In any case, it is an effective tool widely used in power relations, whether implicitly or explicitly, sometimes self-consciously, sometimes not. Our intention here is not to complain about discrimination itself, but to point out the inconsistency between the discourse on multiculturalism, on the one hand, and these common forms of discrimination on the other.

\section{Public Sphere, Public Space and the "Imagined Public"}

The distinction between public and private domains causes much confusion. Where do we draw the boundary between the public and the private? According to Giddens (1991), " the public domain is that of the state, while the private is that which resists the encroachment of the state's surveillance activities".

Keeping this distinction in mind, we would like to put forth a few propositions that are usually assumed to define "public space" in terms of activities and people involved: (1) activities that take place in public spaces are open to scrutiny of others; (2) the kinds of activities that take place in public spaces interest the "publicat-large", and address broader issues beyond persons and personalities; (3) public spaces are inclusive; entry is relatively unrestricted (entrance is not limited to an exclusive class, occupation, group or status of people); (4) public space implies free access; it is open to the enjoyment of anyone free of charge. These are stated, ideal and probably legally provisioned for characteristics. However, what usually happens 
is that there is a wide disparity of situational experiences. Sometimes the variation is so large that we might speak of an "imagined public". Some people have completely rejected the distinction between the concepts of public and private. (In a light-hearted comment, Martha Rosler wrote: "How can there be said to be a private sphere when millions are told simultaneously to insert suppositories in order to gain haemorrhoid relief?" she asks rhetorically, and continues, "and how can there be said to be a public when most of the audience is apparently unconcerned with this simultaneity of address, and even with whether or not the message applies to them?" (in Foster, 1987, p. 15).)

The Fine Arts concept "imagined public" can be useful in this context. As far as art appreciation is concerned, an imagined "public for art" was created during the Enlightenment in both France and England, which identified those who were qualified enough to be an "ideal viewer" of art and to respond to art. According to Crow, this "conception of the public for art ... evoked an ideal community that was not limited to the actual collection of viewers and fanciers of art on hand at a given time. 'The public' represented a standard against which the various inadequacies of art's various consumers could be measured and criticised. This public was thus in large part an imaginary entity, its lineaments being drawn equally from the past and from an anticipated future" (Crow, 1987). Just as we might ask who is qualified enough to be an ideal viewer of art, we might now ask who is qualified enough to enter our public spaces. Just as certain audiences would not qualify as "public for art", some individuals would not qualify to enter our public spaces.

\section{Power: exclusion and inclusion}

Let us return to the general propositions we made earlier. Public space is understood to be all-inclusive in terms of the people who can enter and in terms of the activities that take place. How do we then explain the "diverse experiences" of non-European foreigners in Freiburg or Arendal, that we mentioned earlier? What about the other examples we gave outside the European context, the ones about the shopping mall in Istanbul and the condominium contract in Florida? One key experience that is common to all of these cases is exclusion from reasonably public spaces; and one key word that relates to all of these instances is "power". In each case powerless groups and individuals are excluded from supposedly inclusive spaces. Moreover, as a result of the internalisation of this exclusion, sometimes these powerless individuals censor themselves and self-impose limitations.

In our examples of inclusions and exclusions, a few key renditions are regarded as explanatory. These "key renditions", that we have extracted from various conversations, are as follows:

- It is political and/or it is about class. For example, "they do not allow poorly dressed people in a stylish shopping mall, because they may be terrorists".

- It is about legal enforcement, about crime prevention. For example, "there is a reaction against immigrants because some have been involved in narcotics smuggling". (However, the person who gave us this explanation added her own 
evaluation of this rendition: "individual cases seem to be generalised. Some do smuggle, of course, but not all of them!")

- It is economic. For example, "certain groups of street vendors are treated poorly by certain others because of vested interests".

- It is about culture. For example, "immigrants do not belong here because they don't understand; they don't know; their culture is different".

This last rendition is the most common one and the one that best applies to the case of non-European immigrants in Europe. Exclusions, whether they are forced, or internalised and self-imposed, are readily explained by "cultural differences". However, to exclude a group of people just because they are "different" is not politically correct, especially at a time when multiculturalism is so popular. Therefore, these differences are reformulated into more acceptable arguments. For example, instead of saying that certain people are not acceptable because they are different, if it is stated that their practices are "less hygienic, less healthy, more dangerous", and so on, then there is an "objective" reason for their exclusion. We are not assuming a post-modern stance here, and we are not going to argue for extreme cultural relativism in which "anything goes". Moreover, though there is a tendency to exaggerate in many European "situations", we do not deny that certain practices are indeed unsanitary. However, let us admit that scientific, positivist and universal language provides armoured arguments.

One of these armoured arguments, in the context of cultural diversity, albeit not as powerful as health care, relates to aesthetics. As with health-related arguments, aesthetic arguments are also made using a universal language and assuming an objective position. Therefore, as with scientific arguments, they are impersonal. If a certain object is "tasteless", "ugly", "disgusting", "stinky", etc., you cannot help but reject it. You cannot be blamed for rejecting an unpleasant object because it is not you, the subject, who is responsible for the rejection, but the object itself. Speaking of aesthetic judgements as if they involve universally applicable and measurable criteria is quite common. This brings us to a discussion of aesthetics within the context of cultural diversity and discrimination.

\section{Universal Aesthetics as a Tool of Discrimination}

In the early 1980s, during an informal conversation on the subject of Turkish workers in Germany, a highly educated Turkish professional said, "but the way they dress is really tasteless", and the others present strongly agreed. They uttered similar statements: "The colours those women wear. God. Pinks and greens on bright 'tomb green' and yellow. Floral pyjama bottoms under chequered skirts. Awfully ugly. In horribly bad taste."

Underlying these comments was the assumption that there exists some sense of universal aesthetics that applies to all humanity, unrelated to cultural concerns. What, if any, are the criteria for judging beautiful versus ugly, tasteful versus tasteless, or good versus bad taste? Historical and contemporary views of "beauty", in philosophy and aesthetics, are numerous, which fall outside the scope of this 
paper. It suffices to say here that there are various metaphysical, idealist, historicalmaterialist and ontological views of "beauty". Hence, what we consider to be beautiful, and the criteria with which we define it, cannot be divorced from a broader philosophical stance and world view (see for instance Tunali, 1979). In any particular society, perhaps within a sub-population and at a particular time in history, we may come up with a set of criteria with some degree of agreement by which beauty and ugliness are assessed. Yet, how is it possible to identify universal criteria?

Theoretical and philosophical approaches to aesthetics, since its establishment as a separate "science" in the middle of the 18th century, have varied a great deal. Philosophers have focused on, on the one hand, the various qualities of the aesthetic object itself, and on the other, the attitude, perception, contemplation, conceptualisation and emotions of the subject.

Aesthetics, whether defined as "the science of sensuous perception," or "the philosophy of taste, or of the perception of the beautiful" (The Shorter Oxford Dictionary, cited in Layton, 1991, p. 12) is a complex concept that is intimately linked with the social and cultural context within which it is evaluated. As Raymond Firth had pointed out, all peoples, including non-literate ones, have the same "aesthetic sensibilities and judgements as Western peoples" (quoted in Layton, 1991). Harmony, rhythm and proportion are among the major criteria by which aesthetics is judged, yet what is particularly considered harmonious, rhythmical, or proportional depends on the society from which an art object or an everyday object comes. Layton, for example, who discusses various African sculptures in their cultural context, concludes that, "aesthetic values are not universally expressed in exotic carvings, or other forms of visual expression, but are rather specific to certain aspects of other cultures" (1991, p. 11). "We cannot, as self-respecting anthropologists, assume right from the start that people the world over utilise the same aesthetic criteria as ourselves", he continues, "even in our own history, fashions have changed radically" (1991, p. 12). Or as Crow (1987) comments: "any dissenting practice depends for its meaning on the existence - and the strength-of what it opposes. If we grant that pop art was interesting for its populism or for its irony, it would be because those qualities could be read against the apparent elitism and humourless seriousness of high modernism" (in Foster 1987, p. 1).

\section{Aesthetic Appreciation across Cultures}

Appreciating, evaluating and enjoying unfamiliar experiences, like unfamiliar art, is a double-edged sword. Problems arise whether the unfamiliar is admired and celebrated, or disliked and rejected. On the one hand, if aesthetics is taken out of its social and cultural context, especially in a powerless situation, it is easy to dismiss the unfamiliar as "tasteless", "inharmonious", "disproportionate", or "irregular", etc. We can refer to the case of the Turkish workers in Germany whose dresses are labelled "really tasteless". Yet, anthropologists who have focused on cross-cultural studies of art maintain that universal aesthetic values do not exist.

Given that there are no universal values, it only makes sense to view objects in 
their social context. Two themes within the study of aesthetics are relevant here; namely, "perception in context", and "empathy". For a good example of "perception in context", imagine that the exact same outfit worn by a Turkish immigrant woman in Germany, the same pinks and greens, the same chequered skirt on the same pyjama bottoms or baggy pants, would be worn by a model in a fashion show in Paris. To understand "perception in context", all we have to do is to compare our aesthetic appreciation of both situations. By empathy, what is meant is the identification of the subject with the object. As the folk wisdom goes, "good intentions go a long way". Shared meanings are needed for such empathy. As Layton has stated, "sometimes work of art appear to derive their effect as much from their imagery as from their form" (1991, p. 22). In both verbal and plastic arts, the particular images used or referred to make sense and can only be understood with some contextual knowledge.

On the other hand, however, if the unfamiliar is considered only in its context, there is always the danger of ghettoisation, and the patronisation of the "ethnic" or the "heterodox". These belong by definition outside the mainstream, orthodox, dominant and thus powerful. As an example, we will quote the same woman who had lived in Germany for 3 years: "I wonder if Westerners think, deep down: those non-Westerners are less intelligent. I suppose they do. When I was taking a language course in Germany, we read a couple of poems from our textbook written by Turks living in Germany. They were horrendous things, but our teacher kept on commending them and saying, "how nice!" as if she was talking about the work of lesser people. The poems were good enough for Turks."

Thus, cross-cultural appreciation of taste, quality and beauty, in other words aesthetics, introduces a dilemma that is difficult to resolve. The dilemma here is that, whether an everyday object is despised (like a Turkish woman's dress), or a folk-art is honoured (like a Turkish immigrant's poem), the power situation is maintained and further reproduced. We cannot begin to solve this dilemma here. All we can say is that it is impossible to reach cross-cultural aesthetic appreciation outside the power relations and the social context.

Recently, in another informal conversation, a Turkish woman who had lived in Germany for 3 years recalled: "One Sunday, I was wearing shorts in Mannheim. I suppose they were a little too short. An old woman I met in the street, probably in her seventies, said to me, 'you cannot wear this on a Sunday'. She herself was wearing a very low-cut top without a bra. I confronted her, but she wouldn't hear it ... Some of our friends were turned away from the doors of several discos and looked for one where they were accepted. They were given an excuse about their attire. These friends were university graduates and some worked as finance managers and bankers in Germany. 'Bad dressing' is just an excuse. I don't think it will matter even if they dress well. I think it will take a couple of generations for Germans to accept Turks."

At this point we agree with Lukacs (1991), who, in his theory of aesthetics, avoided a mechanical opposition between life and art, opposed classical theories of aesthetics in which independent, disconnected aesthetic categories are explored in isolation, and attempted to devise his theory of aesthetics from the starting point of 
ordinary, daily life. In the context of cultural diversity, we argue, as Lukacs did, against a "specialisation" in the area of aesthetics, because the same "laws" of aesthetic relations seem to be at the root of the power relations between the non-European immigrants and their "hosts". Even outside Europe, their appreciation of non-European art has been linked to the events of world history. Numerous critical studies have looked into the motivation behind the "European interest in the non-European", and as Layton summarised, "Europeans have tended to assimilate the diverse and independent artistic traditions of other cultures to a monolithic evolutionary or diffusionist scheme at whose centre lie their own specific experiences".

\section{Conclusion}

We would like to reiterate our point concerning the restrictions imposed on cultural expression. With all due respect to those Europeans who struggle for the democratic participation and freedom of expression of minorities in the "public sphere", the picture we see on the cultural diversity front seems to be rather bleak. The stated ideals of cultural diversity and multicultural expression, and the consequent implication that diverse cultures are welcome to participate equally in public spaces are probably well-intentioned and well-meaning, but they amount to nothing more than lip-service to a myth of multiculturalism.

The power differences in culturally diverse communities prevent a desirable form of multiculturalism where, in Hannerz's words, there is "an intellectual and aesthetic stance of openness toward divergent cultural experiences". This intellectual stance may be provided, to be optimistic, through multicultural educational programs which are geared not only to instilling a taste for appreciating the aesthetics of the Other, but also raising people's consciousness so that they will be eager to unlearn their already established aesthetic norms and unquestioned cultural categories. To restate our opening quotation from Epictetus, "it is impossible to begin to learn that which one thinks one already knows".

Address for correspondence: Zerrin G. Tandogan, Bilkent University, Department of Political Science and Public Administration, 06533 Bilkent, Ankara, Turkey. Fax: +90312 2664960.E-mail: <zerrin@bilkent.edu.tr> or <incirli@bilkent.edu.tr>

\section{References}

Coote, J. \& Shelton, A. (Eds) (1992) Anthropology, Art and Aesthetics. Oxford: Clarendon Press. Crow, T. (1987) The birth and death of the viewer: on the public function of art. In: FosTER, H. (Ed.) Discussions in Contemporary Culture. Number One, pp. 1-8. Seattle: Dia Art Foundation.

Foster, H. (Ed.) (1987) Discussions in Contemporary Culture. Number One. Seattle: Dia Art Foundation.

Giddens, A. (1991) Modernity and Self-Identity. Polity Press.

GreENFELD, L. (1989) Different Worlds. A sociological study of taste, choice and success in art. New York: Cambridge University Press. 
HanNerz, U. (1990) Cosmopolitans and locals in world culture. Theory, Culture and Society, 7. Hatcher, E.P. (1985) Art as Culture: An Introduction to the Anthropology of Art. New York: University Press of America.

Kagan, M. (1982) Güzellik Bilimi Olarak Estetik ve Sanat (Aesthetische Vorlesungen). Translated by AzIz ÇALISLAR. Altin Kitaplar Yayinevi, Bilimsel: Sorunlar Dizisi.

Layton, R. (1991) The Anthropology of Art. Cambridge: Cambridge University Press.

LuKacs, G. (1981) Estetik, Vols I and II. Translated by Ahmet Cemal. Istanbul: Payel Yayinlari. METCALF, B.D. (Ed.) (1996) Making Muslim Space in North America and Europe. Berkeley, CA: University of California Press.

Shelley, M. \& WINCK, M. (Eds) (1993) Aspects of European Cultural Diversity. London: The Open University, Routledge.

Tunal, I. (1979) Esetik. Istanbul: Cem Yayinevi, Kültür Dizisi.

VerTOVEC, S. (1996) Multiculturalism, culturalism and public incorporation. Ethnic and Racial Studies, 19(1).

YETKIN, S.K. (1947) Estetik. Istanbul: Remzi Kitabevi. 